\title{
Developing Situations of Tea Plucking Machine
}

\author{
Yu Han1,2, Hongru Xiao'2*, Guangming Qin², Zhiyu Song², Wenqin Ding2, Song Mei² \\ ${ }^{1}$ Graduate School, Chinese Academy of Agricultural Science, Beijing, China \\ ${ }^{2}$ Production Machinery Engineering and Technology Research Center of Special Economic Crop, Nanjing \\ Research Institute for Agricultural Mechanization, Ministry of Agriculture, Nanjing, China \\ Email: ${ }^{*}$ hrr2712@sina.com
}

Received 7 January 2014; revised 7 February 2014; accepted 14 February 2014

Copyright (C) 2014 by authors and Scientific Research Publishing Inc.

This work is licensed under the Creative Commons Attribution International License (CC BY). http://creativecommons.org/licenses/by/4.0/

c) $\underset{\mathrm{EY}}{\mathrm{C}}$ Open Access

\section{Abstract}

To acquire the developing trend and ways of mechanization of tea plucking, with analyzing the developing backgrounds and situations of tea plucking machine both at home and abroad, this paper obtains the conclusion that there are several countries that have conducted a lot of studies on tea plucking machine, such as Japan, England, France, India, Australia and Argentina. Among others, Japan goes ahead, where lots of researches have been conducted in the highest developing level. The article also analyses the reason why China has a poor mechanization of tea plucking and points out existing problems. Finally, some advices and measures for developing Chinese domestic mechanization of tea plucking are given.

\section{Keywords}

Tea Plucking Machine, Development, New Techniques, Suggestion

\section{Introduction}

Tea has been the most popular and healthy beverage around the world. Chinese tea industry has stepped into a fast-developing period, with a more and more prosperous production. Nevertheless, the development has been restricted seriously for the underdevelopment of tea plucking machines under the circumstance that Chinese farming population has been reducing since 2000. Nowadays, what badly needs to be solved is the development of tea harvesting mechanization [1]. The paper points out the existing problems, the later developing ways and gives out some instructive suggestions by analyzing and studying the developing history and present situations of tea plucking mechanization.

*Corresponding author. 


\section{Development Situations}

\subsection{Development Abroad}

Japan studied tea plucking machines first around the world. Began with big scissor since 1910, Japan has investigated the small power tea plucking machine, tea pruning machine, self-propelled tea plucking machine, ride-on tea plucking machine successively, all which were reciprocating cutting and air-swept-collecting type [2], such as LU DAO III tea plucking machine, tea plucking machine mount on CHA SHI II tractor and COROLLA tea plucking machine. COROLLA has good travel performance, a neat plucking surface and less lose in tea leaf collecting, for its track chassis [3]. Around 1970s, tea plucking machine in Japan, according to the principles, could be classified into reciprocating cutting type, spiral hob type, horizontal-circle blade type, spiral roll-fold type and so on. Up to now, Japan has realized mechanization of tea harvesting [4].

The former Soviet Union imported tea plucking scissors form Japan at first in 1929. After 1930, some agricultural scientists began studying and designing tea plucking machines, whose masterpiece were mostly reciprocating cutting type. And, this type was developed into self-propelled type later, which is applied national-wide in 1970 [5]. Now Russia has realized mechanization of tea harvesting too.

England, France, India, Australia and Argentina have carried out some studies about it separately to various extents [6]. Today, all these countries have, successively, realized mechanization of tea harvesting.

In recent years, Japanese scientists have conducted lots of studies on self-propelled tea plucking machine. The most representative one is self-propelled and ride-on type tea plucking machine designed by Terada Seisakusho Co., Ltd., which has a high-clearance track chassis, a cutter flexible-adjusted with its height, and a hydraulic propelling system. With the track drove by hydraulic system, it could travel flexible in complex tea garden. While travelling along the tea rows, it rides on the tea trees (two tracks in the ether side of trees) and the cutter move on the top of tea crown. Except moving forward, the cutter has another reciprocating motion of its two blades, which cut the tea leaf off directly. Last, the cut leaves will be collected into mesh bag with air-swept collecting system. This machine liberates the farmer from heavy labors in some extent. A lot self-propelled tea plucking machines of this type were developed at the same time. And, many patents of tea plucking machine have been granted, such as a kind of tea leaf picking machine [7], crawler-type tea harvesting machine [8], rid-on type tea plucking machine [9], self-propelled tea plucking machine [10] [11].

Through analyzing developing progress, we know the tea plucking machines appeared in the countries mentioned above, according to working principles, could be classified into reciprocating cutting type, spiral hob type, horizontal-circle blades type, spiral roll folding type, among which reciprocating cutting plucking machine was most widely used for its high harvesting quality and efficiency [12].

\subsection{Development in Domestic}

Studding of tea harvesting mechanization began in 1958 in China. Until 1970s, the studies had been widely carried out, resulting in the designs and applications of tea plucking machine of manual type, electrical type and maneuvering type [13]. After 1980, China begins cooperating with foreign companies to produce tea plucking machine. With the supports of government, Chinese engineers have designed out the tea plucking machine of reciprocating cutting type, spiral hob type, horizontal-circle blade type, spiral roll folding type successively after digesting, absorbing and recreating the technologies introduced from abroad, like double-carried picking machine (CS110) and double picking machine (4CSW900).

In recent years, dozens of main kinds of tea plucking machine have appeared in Chinese domestic market, all which are reciprocating cutting type propelled by manual force, motor or electric, with a relatively high integrity rate and quality of harvested tea sprouts. Among them, the one propelled with gasoline engine was widely used for having a sufficient power source and good practicality to sloping land. The best operational effectiveness of those machines are as follow [14], stand regulated sprout and leaf harvested reaches to $50 \%-60 \%$, integrity rate of sprout and leaf $75 \%$ around, net rate of picking up to $85 \%$ to $90 \%$. The commonly used machine models are shown in Table 1.

Studies on small tea plucking machine are still being carried on. There are lots of latest research achievements, like a kind of DC tea plucking machine design by GRACE Co., Ltd. [15], Zhejiang, China, a kind of electrical tea plucking machine developed by GUO Sufang [16] and his team. The former consists of a DC motor, reducer, picking system and so on, and has a small size in volume and a reusable battery, so that it is rather convenient 
Table 1. Current commonly used machine.

\begin{tabular}{|c|c|c|c|}
\hline Model Type & Blade Type & Producer & Note \\
\hline NV45H (Single-carried ) & Flat & Kawasaki in Zhejiang & Assembly of imported \\
\hline 4CD-330 (Single-carried ) & Flat & Picking Machinery Factory in Hangzhou & Null \\
\hline AM-100E (Single-carried ) & Flat & Ochiai Cutlery Changsha & Assembly of imported \\
\hline NCCZ-1000 (Double-carried) & Arch & China Nanchang Aircraft Manufacturing Company (CNAMC) & Null \\
\hline 4CSW-1000 (Double-carried) & Arch & Ningbo Electric motor Factory & Null \\
\hline 4CSW-910 (Double-carried) & Arch & Picking Machinery Factory in Hangzhou & Null \\
\hline CS-100 (Double-carried) & Flat, arch & Yang Ming tea machinery factory & Null \\
\hline V New Z-1000 (Double-carried) & Flat, arch & Ochiai Cutlery Changsha & Assembly of imported \\
\hline PHV-100 (Double-carried) & Flat, arch & Kawasaki in Zhejiang & Assembly of imported \\
\hline
\end{tabular}

for using in the teagarden with much terrain complexities. The latter add a cooling system up to brushless DC motor, which extends the continuing operation period, as well as the life time of the machine. In addition to, LIU Hedi [17] has designed a piece of device for power connecting and locking with one more elastic rod and mandrill. While working, with the tensile force of elastic rod, the mandrill digs into the soft shaft to lock it; once the mandrill pulled outwards, the soft shaft will be unlocked. This device has a so considerable lock force to soft shaft that the connection will not start for vibration, as well as much flexibility and convenience in operating.

Furthermore, studies on self-propelled machine were also carried out in China. For example Long Chaohui [18] invented a kind of tea plucking machine with four rollers installed on the bottom of its body support frame, which could be pushed along tea rows without being carried by human. Though liberating farmer from heavy physical labor to some extent, it has a restricted requirement for road paved along the tea row, resulting in a high cost of tea garden construction. Another one [19] was designed by Nanjing Research Institute for Agricultural Mechanization Ministry. It is an innovation from self-propelled tea plucking machine of Japan, which, with adjustable chassis clearance and cutter height, hydraulic transmission for power, and much intelligence in operating, is more suitable for Chinese tea garden. The innovation point is that it has a controller to control the track travelling in a line. It liberates farmers from heavy work completely. Structures of the electrical plucking machine, single and double carried and self-propelled could be obtained from Figure 1.

As we know, cutting has a side effect on germination of next new sprouts more or less [20]. Based on this, several researchers have studied the machines with new plucking principles yet. For instance, Xiao Yuhuan [21] has designed a machine, which picks the tea sprouts with its roll plates (could rotate around axis of itself), rubber sheets assembled at the end of its blunt arch blades installed near to plates, while machine moving, the plates rotating, the sheets shaving away from the blunt blades. The approach with much success in avoiding damages to new sprouts, however, still needs to be improved in efficiency and harvesting quality.

Another masterpiece is a tea plucking robot designed by Nanjing Research Institute for Agricultural Mechanization Ministry, which is still experimentally studied in laboratory. The robot (Figure 2) recognizes the tea sprouts with binocular stereo computer vision system and picks the objects with its two-finger hand, which imitates the manual picking actions completely, sprouts pulled off but not cut. First, the vision system takes picture of tea crown surface. Then the computer processes the picture and distinguishes the tender sprouts from other tea leaves, the space-position information of distinguished sprouts computed out and saved. Next, the controller sends the moving instructions to actuators in three directions $(\mathrm{X}, \mathrm{Y}, \mathrm{Z})$ that drive the manipulator (two-finger hand) to prescribed destination after planning the optimized moving path according to recognized space-position information. After the hand arrived at the picking spot, the controller will receive the feedback signal and send the pick-starting instruction to the actuator for picking. Once the sprout picked off, it will be inhaled into collecting box by air-sucking collecting system. These procedures are repeated again and again until all the recognized sprouts are picked off, and the next circulation will start with next picture. The project is still going on, some problems appeared. Such as, the visual system does not work well while the wind swings the sprouts or natural light is weak; and, its efficiency is lower markedly than manual picking. All these needs to be resolved in further studies.

\section{Problems}

Although China is the birthplace of tea cultivation and producing [22], it has a poor development of mechaniza- 


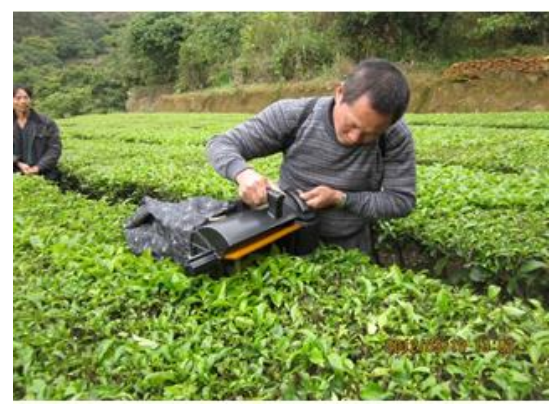

(a)

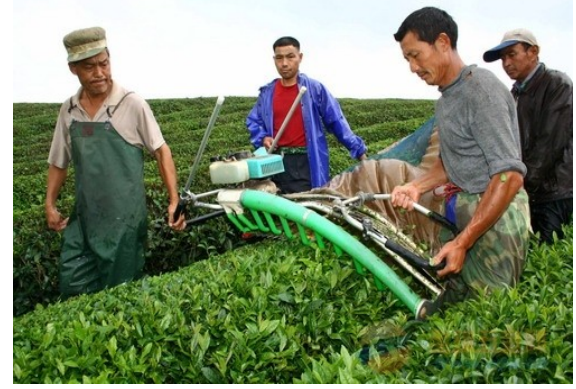

(c)

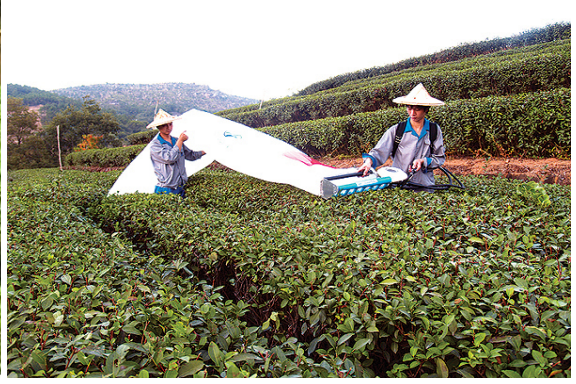

(b)

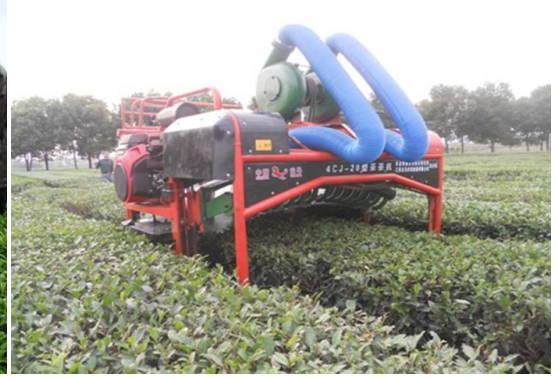

(d)

Figure 1. Four different kinds of tea plucking machine.

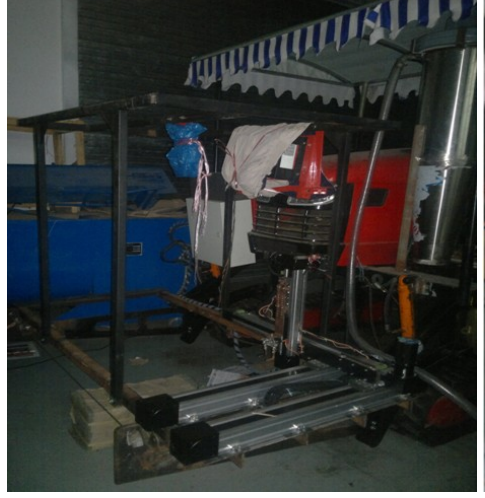

(a)

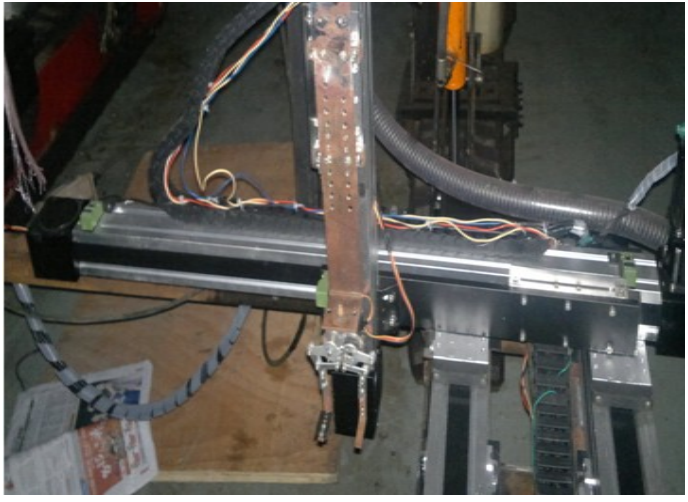

(b)

Figure 2. Tea plucking robot. Note (a) tea picking robot; (b) manipulator.

tion of tea plucking. There are three reasons, in our opinion, accounted mainly for the results. First of all, there were no demands of tea plucking machine for the sufficient supply of human labors last century. Since, it was not until the end of last century that much attention was absorbed in tea harvesting mechanization. Next, applications of new technologies and sciences in agricultural field are always lagging behind those in the industrial areas, resulting in less automatic and intelligent of agriculture machinery. Last but not the least, Chinese people have rather hash requirements for tea qualities, living in the background with rich Chinese unique tea cultures, which makes the mechanization of tea harvesting more difficult. All in all, it was all these foundations that made the current mechanizing situation of tea plucking machineun satisfactory.

According to current developing conditions in China, a lot of problems need to be resolved. First, there is no standardized planting pattern for tea garden. Various patterns need different type of machines, which leads to a chaos of investigations and market. Secondly, the domestic tea plucking machines are mostly imitations of ones from Japanese regardless of only a few innovations. These machines are not suitable for Chinese tea very well, for Chinese people have different tea drinking habits from Japanese. For example, Chinese like integrated tea, but Japanese care little about whether it is integrated or broken. Since then, tea plucking machines that just pick tea 
off in spite of integrate rate of harvested tea leaves play well in Japan only, but not in China. Last, there are only a few research institutes devote to investigations on tea plucking machine, and less government supports.

Only these problems are emphasized and to be resolved, can tea plucking machine develop as fast as industrial machinery.

\section{Conclusion}

Analyzing from the developing progress of mechanization of tea plucking machine all around the world, it is evident that tea plucking machine, according to working principles, could be classified into reciprocating cutting type, spiral hob type, horizontal-circle blade type, spiral roll folding type, among which reciprocating cutting plucking machine has been widely applied for its high harvesting quality and high efficiency. Almost all the tea plucking machines in china are this type.

Among the tea-growing countries, Japan, England, France, India, Australia and Argentina all have realized mechanization of tea harvesting respectively. However, tea harvesting in China just stands in a semi-mechanized state level. To prosper its tea industry, it is necessary for China to improve its mechanization level of tea plucking, not only researching, designing, and producing, but also popularizing.

All in all, with the development of science and technology, bulk tea is likely to be mechanically picked with few human interventions; further, high-quality tea needs to be plucked with more intelligent robots.

\section{Suggestions for Developing}

In China, human labor is decreasing sharply, so the demands of harvesting machine for tea are increasing significantly. To improve development of tea harvesting mechanization, here are several suggestions:

1) Popularize standardized planting pattern national-wide to standardize the model type of tea plucking machine, which makes the aims and standard rules of design and manufacturing more explicit. Only by this, can tea plucking machines be standardized and popularized more easily, can mechanization of tea plucking speed up.

2) Optimize the existing cutter of plucking machine or innovate new kinds of picking principles to improve plucking qualities, which is the key point of tea plucking machine. The poor quality of plucked tea of existing plucking machine accounts mainly for the bad popularizing of the machines. So, lots of further studies and investigations should be involved to that key point.

3) Break through constraints of the traditional concepts that the agricultural machines are simple and crude and that peasants are illiterate. Combine electronics, hydraulics and control technology with the traditional machine to promote its automation and intelligence. Chinese farmers must be change to be intelligent and acquainted enough to operate the so called advanced machine next few decades. Only the equipment improved first, can they change to adapt to them subsequently.

4) Learn technologies and experiences from industrial robot studying to research and exploit high efficiency, high precision and more intelligent picking robot to harvest high quality tea which is rather important for prosperous developing of quality tea industry. Such applications of intelligent robots as medical robot, industrial robot, domestic robot, agricultural robot have been widely used in abroad, like America, Japan and so on. Thus, it is the agricultural robot that will be leader of the agricultural mechanical equipment (whatever it is used for) in the near future, tea plucking robot absolutely being counted in.

5) The government should Increase capital investment and strengthen supervision for safe of producing and applying of tea plucking machine. Both the sufficient research founds and a favorable developing circumstance is needed to the healthy development of mechanization of tea plucking. To realize a fast development, the government has the responsibilities to supply good conditions for researching and developing of new products, create a safe developing circumstance for producing and utilizing.

\section{Acknowledgements}

The authors thank the National Science and Technology Support Program during the 12th Five-Year Plan Period (Grant No. 2011BAD20B07-3),The national Spark Program project (2013GA6900013)—the organic management technology development and demonstration of tea mechanization, Modern agricultural technology system post scientist Fund (CARS-23)—-tea industry technology system and Industry specific (201303012)—comprehensive tea mechanization technology. 


\section{References}

[1] Suzuki, K. (1977) Studies on the Wide Application of the Self-Propelled Plucking Machine. Tea Research Journal, 45, 63-72. http://dx.doi.org/10.5979/cha.1977.63

[2] Nakano, T. (1998) Influences of Plucking Position on Yield and Quality of Tea in Mechanically-Plucked Tea Bush. Tea Research Journal, 86, 11-17. http://dx.doi.org/10.5979/cha.1998.11

[3] Lin, X.H. (1989) Only Realized Mechanization of Tea-Leaf Picking, Can Tea Producing Industry Developed. Fu Jian Tea, 15, 4-7.

[4] Xiao, H.R., Qin, G.M. and Song, Z.Y. (2011) Study on Developing Strategy of Mechanization of Tea Producing. China Tea, 2, 7-10. (In Chinese)

[5] Qiu, P.X. and Chen, C. (1993) Developing History of Tea Pruning Machine and Tea Plucking Machine. History Related by Tea Picker, 38, 27-30. (In Chinese)

[6] Duara, M. and Mallick, S. (2012) Tea Industry in Assam (India): Issues of Migration and Gender Discrimination. Proceedings of International Conference on History and Society Development (ICHSD2012), Bangkok, 24 November 2012, 174-177.

[7] Erada, J.C. (2008) Traveling Type Tea Plucking Machine. JP Patent No. 2008301831.

[8] Aokiha, J.A. (2011) Tea Leaf-Picking Mchine. JP Patent No. 2011193754.

[9] Terada, J. and Aoyama, T. (2010) Aeling Tea Leaf Plucking Machine. JP Patent No. 2010057421.

[10] Terada, J. (2010) Raveling Type Tea-Leaf Plucking Machine for Sweeping Dew. JP Patent No. 2010148519.

[11] Zhang, B.C. and Hua, J. (2013) Tea Machine Base, Control Method Thereof and Tea Machine. US Patent No. 2013059049.

[12] Sugimura, S.J. (2012) Device for Setting Height of Plucking Device of Traveling Type Tea Leaf Plucker. JP Patent No. 2012024025.

[13] Zheng, N.H. and Wang, Z.K. (2011) Mechanization of Tea Picking: Break Out the Bottleneck of Tea Industry. Chinese country Technology and Science, 12, 14-17.

[14] Hu, J. and He, Z.F. (2011) Situations and Expectations of Trimming and Picking Machine for Tea Tree. Agricultural Equipment and Technique, 37, 21-24. (In Chinese)

[15] Hu, X.G. (2012) Dc Tea Plucking Machine. CN Patent No. 102668812 A.

[16] Guo, S.F. (2012) Environmental Protection Energy-Saving Electric Tea Plucking Machine. CN Patent No. 202524769 U. (In Chinese)

[17] Liu, H.D. (2012) A New Type of Power Connector of Knapsack Tea Plucking Machine. CN Patent No. 202140457 U.

[18] Long, C.H. (2012) A Kind of Tea Plucking Machine. CN Patent No. 202444808 U.

[19] Han, Y., Xiao, H.R., Qin, G.M., Song, Z.Y. and Ding, W.Q. (2013) Late Research Situation and Trend of Tea Garden Machinery in China. Journal of Chinese Agricultural Mechanization, 34, 13-16.

[20] Owuor, P.O., Kamau, D.M. and Jondiko, E.O. (2008) Responses of Clonal Tea to Location of Production and Plucking Intervals. Food Chemistry, 115, 290-296. http://dx.doi.org/10.1016/j.foodchem.2008.11.073

[21] Xiao, Y.H. (2012) A Kind of Tea Plucking Machine. CN Patent No. 202496217 U.

[22] Liu, Z. (2010) Situations and Suggests of Our Country’s Tea Standard. Tea Communication, 23, 27-30. 